\title{
Title page / Table of Contents
}

Vol. 16,1997

Neuroepidemiology

Founded 1982 by B.S. Schoenberg, continued by M. Alter (1989-1996)

\section{Editor-in-Chief}

P.B. Gorelick, Chicago, 111.

Deputy Editor

W.A. Rocca,

Rochester, Minn.

\section{Editor Emeritus}

M. Alter, Philadelphia, Pa. 


\section{Editorial Board}

M.Z. Al Kawi, Riyadh E. Beghi, Milano M.M. Benhamida, Tunis N.E.

Bharucha, Bombay G. Boysen, Copenhagen V. Chandra, New Delhi X.-M.

Cheng, Beijing R. D'Alessandro, Bologna J.F. Dartigues, Bordeaux G. Dean, Dublin G.C. Ebers, London, Ont. G. Friday,

Westborough, Mass. E. Granieri, Ferrara W. Hader, Saskatoon E. Kahana, Ashkelon W.C. Roller,

Kansas City, Kans. A. Korc2yn, Tel Aviv 
J.F. Kurtzke,

Washington, D.C. C. Mangone, Buenos Aires J. Matias-Guiu, Alicante R.P.

Mayeux,

New York, N.Y. S.-M. Lai, Kansas City, Kans. C.A. Molgaard,

Wichita, Kans. M. Musicco, Milano W J. Mutch, Dundee S.-C. Nai, Taipei K.

Nakashima, Yonago A.H. Rajput, Saskatoon R.L. Sacco, New York, N.Y. C.

Tanner, Sunnyvale, Calif. W.C. Wiederholt,

La Jolla, Calif. 
Basel $\bullet$ Freiburg $\square$ Paris $\bullet$ London $\bullet$ New York $\bullet$ New Delhi • Bangkok •

Singapore $\bullet$ Tokyo $\bullet$ Sydney 
Contents Vol. 16, 1997

\section{Neuroepidemiology}

No. 1

\section{Original Papers}

1 Effects of Brain Injury on College Academic Performance

Gerberich, S.G. (Minneapolis, Minn.); Gibson, R.W. (Minneapolis, MinnVDuluth, Minn.); Fife, D. (Springhouse, Penn.); Mandel, J.S .

Aeppli, D.; Le, C.T.; Maxwell, R.; Rolnik, S.J. (Minneapolis, Minn.); Renier, C. (Duluth, Minn.); Burlew, M.; Matross, R (Minneapolis, Minn.) 15 A Hospital-Based and a Population-Based Stroke Registry Yield Different Results: The Experience in Dijon, France Giroud, M.; Lemesle, M.; Quantin, C; Vourch, M.; Becker, F.; Milan, C; Brunet-Lecomte, P.; Dumas, R. (Dijon)

22 Prognosis of Childhood Epilepsy: A Community-Based Study in Copparo, Italy

Casetta, I.; Granieri, E.; Monetti, V.C.; Tola, M.R.; Paolino, E. (Ferrara); Malagu', S. (Forli); Gilli, G.; Govoni, V.; Carreras, M. (Ferrara)

29 Cognitive Predictors of Dementia in Elderly Community Residents

Dartigues, J.F.; Commenges, D.; Letenneur, L.; Barberger-Gateau, P.; Gilleron, V.; Fabrigoule, C; Mazaux, J.M.; Orgogozo, J.M.; Salamon, R (Bordeaux)

40 Stroke in Kuwait: A Three-Year Prospective Study

Abdul-Ghaffar, N.U.A.M.A.; El-Sonbaty, M.R.; El-Din Abdul-Baky, M.S.; Marafie, A.A.; Al-Said, A.M. (Fehahil)

48 Sociodemographic Factors and Primary Headache Syndromes in a Saudi Community

Abdul Jabbar, M.; Ogunniyi, A. (Riyadh)

No. 2

Original Papers

53 Incidence and Survival of Intracranial Meningioma Patients in Norway 1963-1992

Helseth,A.(Oslo)

60 The Kinmen Neurological Disorders Survey (KINDS): A Study of a Chinese Population

Liu, H.-C; Wang, S.-J.; Fuh, J.-L.; Liu, C.-Y.; Lin, K.-P.; Lin, C.-H.; Wang, P.-N.; Lin, K.-N.; Wang, H.-C; Chen, H.-M.; Chang, R. (Taipei); Larson, E.B. (Seattle, Wash.); Wu, G.-S. (Kinmen); Chou, P. (Taipei); Teng, E.L. (Los Angeles, Calif.)

69 Dietary Vitamin C, Beta-Carotene and 30-Year Risk of Stroke: Results from the Western Electric Study

Daviglus, M.L. (Chicago, 111.); Orencia, A.J. (Indianapolis, Ind.); Dyer, A.R.; Liu, K.; Morris, D.K.; Persky, V.; Chavez, N.; Goldberg, J.; Drum, M. (Chicago, 111.); Shekelle, R.B. (Houston, Tex.); Stamler, J. (Chicago, 111.)

78 Comparison of Neuropsychological Performance between AIDS-Free Injecting Drug Users and Homosexual Men Concha, M. (Coral Gables, Fla.); Seines, O.A.; Vlahov, D.; Nance-Sproson, T.; Updike, M.; Royal, W.; Palenicek, J.; McArthur, J.C. (Baltimore, Md.) 
86 Alzheimer's Disease and History of Blood Transfusion by Apolipoprotein-E Genotype

O'Meara, E.S.; Kukull, W.A.; Schellenberg, G.D.; Bowen, J.D.; McCormick, W.C.; Ten, L.; Pfanschmidt, M.; Thompson, J.D.; Larson, E.B. (Seattle, Wash.)

94 Prevalence of Epilepsy in a Migrant Population near Quito, Ecuador

Basch, E.M. (Boston, Mass.); Cruz, M.E.; Tapia, D. (Quito); Cruz, A. (Limoges)

99 Stroke: Trends in Mortality in Andalusia (Spain), 1975-1992

Cayuela Dominguez, A.; Rodriguez Dominguez, S.;

Lapetra Peralta, J.; Gil Peralta, A.; Rodriguez Arce, A. (Seville)

No. 3

Editorial Review

107 Status of Lipids as a Risk Factor for Stroke

Gorelick, P.B.; Schneck, M. (Chicago, III.); Berglund, L.F. (New York, N.Y.); Feinberg, W. (Tucson, Ariz.); Goldstone, J. (San Francisco,

Calif.)

Original Papers

116 Cerebrovascular Disease Mortality in Spain, 1955-1992: An Age-Period-Cohort Analysis

Guallar Castillon, P. (Madrid); Rodriguez Artalejo, F. (Madrid/Vitoria); Banegas Banegas, J.R.; Guallar, E.; del Rey Calero, J. (Madrid)

124 The Washington Heights-Inwood Genetic Study of Essential Tremor: Methodologic Issues in Essential-Tremor Research

Louis, E.D.; Ottman, R.; Ford, B.; Pullman, S.; Martinez, M.; Fahn, S.; Hauser, W.A. (New York, N.Y.)

134 Survival in Early Onset Dementia: Effects of Urbanization and Socio-Economic Deprivation

Thomas, B.M. (Aberdeen); McGonigal, G. (Edinburgh); McQuade, C.A. (Aberdeen); Starr, J.M. (Edinburgh); Whalley, L.J. (Aberdeen)

141 Reliability of the Modified Mini-Mental State Examination in the Context of a Two-Phase Community Prevalence Study

Bravo, G.; Hebert, R. (Sherbrooke, Quf.)

149 The Prevalence and Severity of White Matter Lesions, Their Relationship with Age, Ethnicity, Gender, and Cardiovascular Disease Risk Factors: The ARIC Study

- j Brno, D. (Chapel Hill, N.C.); Cooper, L. (Bethesda, Md.); Cai, J. (Chapel Hill, N.C.); Toole, J. (WinsftpSalem, N.OJyBryan, N. (Baltimore, Md.); Burke, G. (Winston-Salem, N.C.); Shahar, E. (Minneapolis, Minn.); Nieto, J. (Baltimore, Md.); Mosley, T. (Jackson, Miss.); Heiss, G. (Chapel Hill, N.C.)

\section{KARGEH}

E-Mail karger@karger.ch Fax+41 613061234 http://www.karger.ch 


\section{C) 1997 S. Karger AG, Basel}

The list of contents is available at: http*y/www.karger.ch/jouraals/ned/nedcont.htm 
Editorial

163 Stroke Prevention: Windows of Opportunity and Failed Expectations? A Discussion of Modifiable Cardiovascular Risk Factors and a Prevention Proposal Gorelick, Ph.B. (Chicago, III.)

Guest Editorials

174 Is Psychological Stress a Risk Factor for Cerebrovascular Disease?

Schneck, M.J. (Chicago, HI.)

180 Secular Trends in Stroke Mortality in African

Americans: The Role of Urbanization, Diabetes and

Obesity

GDlum, RJF. (Hyattsville, Md.) 185 Psychometric Considerations When Measuring

Cognitive Decline in Alzheimer's Disease

Nyenhuis, D.L.; Garron, D.C (Chicago, 111.)

Original Papers

191 The Effect on Risk Estimates of Excluding Cases from a Case-Control Study of Ischemic Stroke

Stewart, A. (Baltimore, Md.); Davis, P. (Shreveport, La.); Kittner, S.; Langenbeig, P. (Baltimore, Md.)

199 Epidemiology of Myasthenia gravis in Northwestern Sardinia

Aiello, I.; Pastorino, M.; Sotgiu, S.; Pirastru^M.I.;.Sau, G.F.; Sanna, C; Rosati, G. (Sassari)

207 Epilepsy and Everyday Life Risks. A Case-Referent Study: Rationale, Study Design, and Preliminary Results Beghi, E.; Comaggia, C. (Milano)

No. 5

Guest Editorial

217 Status of Patent Foramen ovale. Atrial Septal Aneurysm, Atrial Septal Defect and Aortic Arch Atheroma as Risk Factors for Stroke

Devuyst, G. (Haine-St-Paul); Bogousslavsky, J. (Lausanne)

Original Papers

224 The Minorities Risk Factors and Stroke Study (MRFASS). Design, Methods and Baseline Characteristics

Tuhrim, S.; Godbold, J.H.; Goldman, MM.', Horowitz, D.R.; Weinberger, J. (New York, N.Y.)

234 Risk Factors for Alzheimer's Disease: A Case-Control Study

Wang, P.-N.; Wang, S.-J.; Hong, C.-J.; Liu, T.-T.; Fuh, J.-L.; Chi, C.-W.; Liu, C.-Y.; Liu, H.-C. (Taipei)

241 A Nationwide Epidemiological Study of Spinal Cord Injury in Geriatric Patients in Taiwan

Chen, H.-Y.; Chen, S.-S.; Chiu, W.-T.; Lee, L.-S.; Hung, C.-I; Hung, C.-L.; Wang, Y.-C; Hung, C.-C.; Lin, L.-S.; Shih, Y.-H; Kuo, C.-Y.

(Taipei) 
248 A Study of Pediatric Brain Tumors and Their Association with Epilepsy and Anticonvulsant Use

Gumey, J.G. (St. Louis, Mo.); Mueller, B.A, (Seattle, Wash.); Preston-Martin, S. (Los Angeles, Calif.); McDaniel, A.M. (Detroit, Mich.); Holly, E.A. (San Francisco, Calif.); Pogoda, J.M. (Truckee, Calif.); Davis, R.L. (San Francisco, Calif.)

Abstracts

257 Regional North American Annual Meeting of the World Federation of Neurology - Research Group on Neuroepidemiology April 18,*i997, Boston, Mass., USA

247 Announcement 256 Book Review

No. 6

Guest Editorials

271 The Use of Screening Instruments for the Detection of Dementia

Ganguli, M. (Pittsburgh, Pa.)

281 Participation of African Americans in Clinical Research

Bonner, G J. (Chicago, 111.); Miles, T.P. (San Antonio, Tex.)

Original Papers

285 Correlates of Change in Cognitive Function in Survivors from the Western Collaborative Group Study

Carmelli, D.; Swan, G.E.; LaRue, A.; Eslinger, P.J. (Menlo Park, Calif.)

296 Phenytoin-Induced Gingival Overgrowth:

A Community-Based Cross-Sectional Study in Ferrara,Italy

Casetta, 1.1 Granieri, E.; Desidera, M.; Monetti, V.C.; Tola, M.R.; Paolino, E.; Govoni, V.; Calura, G. (Ferrara)

304 Prevalence of Multiple Sclerosis in Bulgaria

Milanov, I.; Georgiev, D.; Kmetska, K.; Jordanova, L.; Topalov, N. (Sofia)

308 The Rationale for Standardized Registration and Reporting of Brain and Central Nervous System Tumors in PopulationBased Cancer Registries

Davis, F.G. (Chicago, I1L); Bruner, J.M. (Houston, Tex.); Surawicz, T.S. (Chicago, 111.)

317 Occupational Exposure to Organic Solvents and Sleep-Disordered Breathing

Ulfberg, J. (Uppsala/Avesta); Carter, N.; TalbSck, M.; Edling, C. (Uppsala)

307 Announcement

327 Author Index Vol. 16,1997

329 Subject Index Vol. 16,1997 
